\title{
Profitability of Technical Analysis in the Singapore Stock Market: before and after the Asian Financial Crisis
}

\author{
James J. Kung \\ Ming Chuan University \\ Wing-Keung Wong \\ Hong Kong Baptist University
}

\begin{abstract}
In the aftermath of the Asian financial crisis, a series of reform and liberalization measures have been implemented in Singapore to upgrade its financial markets. This study investigates whether these measures have led to less profitability for those investors who employ technical rules for trading stocks. Our results show that the three trading rules consistently generate higher annual returns for 1988-1996 than those for 1999-2007. Further, they generally perform better than the buy-and-hold (BH) strategy for 1988-1996 but perform no better than the BH strategy for 1999-2007. These findings suggest that the efficiency of the Singapore stock market has been considerably enhanced by the measures implemented after the crisis.
\end{abstract}

- JEL Classification : G14, D92

- Key Words: Asian financial crisis, profitability, technical analysis, moving average, trading range breakout

\footnotetext{
*Corresponding address: James J. Kung: Department of International Business, Ming Chuan University, 250 Chung Shan N. Road, Section 5 Taipei 111, Taiwan, Tel: 886-2-27411362, Fax: 886-2-28809751, e-mail: fnjames@mcu.edu.tw, Wing-Keung Wong: Department of Economics, Hong Kong Baptist University, Hong Kong

○2009-Center for International Economics, Sejong Institution, Sejong University, All Rights Reserved.
} 


\section{Introduction}

More than ten years have elapsed since the outbreak of the Asian financial crisis. During the crisis, the Straits Times Industrial Index (STII), the previous benchmark indicator of the Singapore stock market, plummeted almost 60 percent from a high of 2,007 on 8 July 1997 to a low of 805 on 4 September 1998 ! The crisis prompted the Monetary Authority of Singapore (MAS) to implement an array of reform and liberalization ${ }^{1}$ measures intended to, in the words of the then Deputy Prime Minister Lee Hsien Loong, "rectify existing inefficiencies in the capital markets and sharpen the competitive edge." Today, Singapore ${ }^{2}$ is widely recognized as one of the major world financial centers, surpassing its financial status before the crisis.

The crisis of 1997-1998 could serve as a watershed in the upgrading of Singapore's financial markets. Before the mid-1980s, the brokerage industry in Singapore and the companies listed on the Singapore Exchange ${ }^{3}$ (SGX), according to a June-2004 study by the MAS, were "essentially unregulated." Basically, there were no specific supervision rules and no prudential requirements set for brokerage firms. The Pan Electric crisis ${ }^{4}$ in November 1985 forced the MAS to suspend trading on the SGX for three days to make remedial arrangements and restore public confidence in the stock market. Again in February 1995, the Barings incident $^{5}$ further tarnished the reputation of Singapore as a major Asia-Pacific financial center. In the ensuing years after the crisis, the MAS and the Singapore government have implemented a series of reform and liberalization measures ${ }^{6}$ to upgrade its financial markets.

In fact, many empirical studies present evidence that the Singapore stock market before the Asian financial crisis was far from being efficient. For example, Kester (1990) demonstrates that Singapore stocks offer more profitable opportunities for

\footnotetext{
${ }^{1}$ Kim and Singal (1997) and Kim (2003) point out some major advantages for emerging nations to open up their securities markets to foreign investors.

${ }^{2}$ At present, more than 700 local and foreign financial institutions have business offices in Singapore offering a wide range of financial products and services.

${ }^{3}$ Before 1 December 1999, the Singapore Exchange (SGX) was named the Stock Exchange of Singapore (SES).

${ }^{4}$ The underlying cause of the crisis was that a few brokerage firms excessively financed their clients's share purchases through equity-related forward contracts during a time when stocks on the SES were considerably over-valued. The crisis erupted when individual and institutional investors were unable to meet their obligations on the forward contracts on Pan Electric shares.

${ }^{5}$ On the Barings incident, Timothy Moe, the director of research for Salomon Brothers in Hong Kong, puts it, "the regulatory mechanisms of the Singapore International Monetary Exchange proved woefully inadequate."
} 
market timing than U.S. stocks, both in terms of potential gains and required predictive accuracy. Bailey et al. (1990) and Pan et al. (1991) show that prices in the Singapore stock market display substantial deviations from random walk behavior. Huang (1995), using weekly closing prices of the STII from 1 January 1988 to 30 June 1992, rejects the random walk hypothesis for the Singapore stock market using the variance ratio test.

In perfectly efficient markets (see, for example, Fama, 1970 and 1991; LeRoy, 1982; and Sharpe et al., 1999), it is not possible to make abnormal returns with either technical analysis or fundamental analysis. In this study, we investigate, based on daily closing prices of the Straits Times Index (STI), ${ }^{7}$ whether those reform and liberalization measures implemented after the crisis by the MAS and the Singapore government have improved the efficiency of the Singapore stock market, which in turn has resulted in less profitability for those investors who employ technical rules for trading stocks. Specifically, we partition the 1988-2007 sample period into two equal sub-periods - nine years (1988-1996) before the crisis and nine years (1999-2007) after the crisis - and examine whether there is significant difference in annual returns between the two sub-periods.

To implement, we use three simple but popular technical trading rules - simple moving average, dual moving average, and trading range breakout -- to assess the profitability in the Singapore stock market. The rationale for using them is that if the market is efficient, then it is not possible to make abnormal returns with these trading rules. These three trading rules were used by many researchers (e.g., Brock et al., 1992; Hudson et al., 1996; Bessembinder and Chan, 1998) to examine the efficiency or profitability in some well-known stock markets in the world.

Our implementation of the three trading rules differs from most of the previous related literature in two ways. First, most previous studies ignore two things (e.g., Brock et al., 1992; Bessembinder and Chan, 1995; Fernandez-Rodriguez et al.,

\footnotetext{
${ }^{6}$ Some of the important measures implemented after the Asian financial crisis include the launch of the Singapore Exchange (SGX) in place of the Stock Exchange of Singapore and the Singapore International Monetary Exchange, shortening the settlement period from $T+5$ trading days to $T+3$ trading days to lower settlement risk and raise efficiency, replacing fixed brokerage fees with freely negotiated commissions, setting up risk-based capital requirements to improve competition and access to the industry, lifting all restrictions on qualified investors who wish to trade on the SGX to increase the liquidity and depth of the market, and forming the ASEAN Investment Area (AIA) intended to integrate the stock markets in the five original ASEAN countries (i.e., Indonesia, Malaysia, the Philippines, Singapore, and Thailand).

${ }^{7}$ The STII was replaced by the STI on 31 August 1998.
} 
2000) when computing returns for the trading rules. One is that they ignore trading costs. The other is that they ignore dividends that would be received when the trading rule suggests investing in the market index ${ }^{8}$ and interest incomes ${ }^{9}$ that could be earned when it suggests not investing in the market index. In this study, we improve on previous studies by taking the two things into consideration when computing returns for the trading rules. Second, most previous studies (e.g., Bessembinder and Chan, 1995; Hudson et al., 1996, Bessembinder and Chan, 1998) follow the approach ${ }^{10}$ of Brock et al. (1992) in that, for each trading rule, they calculate two mean daily returns, one for buy signal and one for sell signal. That is, their approach is such that an investor would take a long position in the market index when a buy signal is emitted and, conversely, would take a short position in the market index when a sell signal is emitted. Such an approach of switching between a long position and a short position in the market index is not realistic from a practical sense. In practice, few investors would stay in the market alternating between a long position and a short position, and never stay out of the market -- especially at times when investors are very uncertain about where the market is headed. In some situations, both individual and institutional investors may prefer to stay out of the market for some time. Accordingly, in this study, we calculate the annual return for each trading rule for each of the two sub-periods, taking capital gains (or capital losses) and dividends into account when the rule suggests investing in the market index, and taking interest incomes into account when it suggests not investing in the market index.

The rest of the paper proceeds as follows: Section II describes the three trading rules and their implementation. Further, a one-tailed hypothesis test is set up to test statistically the significance of the returns obtained. Section III presents the data and reports some summary statistics. In Section IV, we discuss our empirical results for the three trading rules and the robustness of our results. Section V

\footnotetext{
${ }^{8}$ In practice, there is no such thing as investing literally in a market index. However, we can implement our trading rules by investing in an exchange traded fund (ETF). A case in point is the StreetTRACKS Straits Times Index ETF. Traded on the SGX, this ETF replicates as closely as possible, before expense, the performance of the STI. Hence, the return from holding such ETF includes not only the capital gains (or capital losses) but also the dividends.

${ }^{9}$ When the trading rule suggests not investing in the market index, the money can be invested in money market account that pays interest based on short-term interest rates.

${ }^{10}$ One objective of Brock et al.'s (1992) study is to test the effectiveness of some technical trading rules based on the Dow Jones Index of the United States. Our objective is to investigate, using the three trading rules as uniform yardsticks, whether there is any significant difference in annual return between the two sub-periods based on the Straits Times Index of Singapore.
} 
concludes this study.

\section{The Three Trading Rules and their Implementation}

The three trading rules used in this study are simple moving average, dual moving average, and trading range breakout (TRB). The $n$-day moving average (MA) on day $t$ is given by

$$
M_{t, n}=\frac{1}{n} \sum_{k=t-n+1}^{t} p_{k}=\frac{1}{n}\left[P_{t-n+1}+P_{t-n+2}+\ldots+P_{t-1}+P_{t}\right]
$$

where $P_{k}$ is the closing price of the STI on day $k$.

\section{A. The Three Trading Rules}

According to simple MA rules, a buy signal is generated when the closing price rises above the $n$-day MA and a sell signal is generated when the closing price falls below the $n$-day MA. When a signal is generated, simple MA rules require that the position be maintained until the closing price penetrates the $n$-day MA again. A popular simple MA rule is 1-100, where the MA is 100 days. To implement, we use the following simple MA rules: 1-20, 1-50, 1-100, 1-150, and 1-200. Each rule is evaluated with bands of $0 \%$ and $1 \%$, making a total of 10 simple MA rules for each of the two sub-periods. A band is used to reduce the number of times an investor would have to move into and out of the market. For example, Brock et al. (1992), Bessembinder and Chan (1998), and Siegel (2002) all use a 1\% band for their trading rules.

According to dual MA rules, buy and sell signals are generated by a short MA and a long MA. Buy (sell) signals are generated when the short MA rises above (falls below) the long MA by a prespecified percentage band. To implement, we use the following dual MA rules: 2-20, 2-50, 5-100, 5-150, and 5-200. Each rule is evaluated with bands of $0 \%$ and $1 \%$, making a total of 10 dual MA rules for each of the two sub-periods.

According to TRB rules, a buy signal is emitted when the closing price rises above the local maximum (i.e., the maximum price over the past certain number of days) and a sell signal is emitted when the closing price falls below the local minimum (i.e., the minimum price over the past certain number of days). In notation, an $m$-day local maximum on day $t(L \max [m, t])$ and an $m$-day local minimum $(L \min [m, t])$ on day $t$ are defined respectively as 


$$
\begin{aligned}
L \max [m, t] & =\max \left[P_{t-m}, P_{t-m+l}, \ldots P_{t-l}\right] \\
L \min [m, t] & =\min \left[P_{t-m}, P_{t-m+l}, \ldots P_{t-l}\right]
\end{aligned}
$$

where $P_{k}(k=t-m, t-m+1, \ldots, t-1)$ is the closing price of the STI on day $k$. That is, a buy signal is emitted if $P_{t}>L \max [m, t]$ and a sell signal is emitted if $<L \min [m, t]$. When a buy signal is emitted, the investor takes a long position in the STI the next day and maintains the position for 10 days. Similarly, when a sell signal is emitted, the investor sells his/her position in the STI the next day and remains out of the market for 10 days. In either case, when the 10 days are over, the investor starts again waiting for a buy or a sell signal. To implement, we use local maximums and local minimums over the preceding 20, 50, 100, 150, and 200 days. Again, each rule is evaluated with bands of $0 \%$ and $1 \%$, making a total of 10 TRB rules for each of the two sub-periods.

\section{B. Implementation of the Trading Rules}

As mentioned in Section 1, our implementation of the three trading rules differs from the majority of previous related studies. For clarity, let us briefly go through the trading process. At the beginning of each sub-period, we start out with $\$ 1$ (in practice, $\$ 1$ can stand for a million or a billion dollars) and wait for a buy signal. When the rule signals a buy, we invest our \$1 at the STI level at that time, taking every item of the trading costs into account. When the rule signals a sell, we sell our investment at the STI level at that time, again taking every item of the trading costs into account. This alternation between buying and selling, according to the signal of the trading rule, continues until we reach the end of the sub-period, at which time we compute the annual return for the rule. As mentioned in Section 1, we include the dividends that will be received when the rule suggests investing in the STI and the interest incomes that can be earned when it suggests not investing in the STI.

Since the three trading rules result in frequent trading, every item of the trading costs is included in our computations. The costs of trading stocks on the SGX include a brokerage fee, ${ }^{11}$ a clearing fee of $0.05 \%$ of the transaction amount, and bid-ask spread. Investors have to pay both brokerage fee and clearing fee when buying and selling stocks. In addition, using recent bid and ask prices of 50

\footnotetext{
${ }^{11}$ As mentioned in footnote 6, the SGX has replaced fixed brokerage fees with freely negotiated commissions after the Asian financial crisis. For institutional investors, the brokerage rate was roughly $0.5 \%$ of the transaction amount before the crisis and $0.2 \%$ of the transaction amount after the crisis.
} 
randomly chosen stocks traded on the SGX, we obtain an estimated bid-ask spread of $0.96 \%$ based on the market capitalization of the 50 stocks.

\section{One-tailed Hypothesis Test}

Here a one-tailed hypothesis test is used. ${ }^{12}$ For buy transactions, the null hypothesis is $H_{0}: \mu_{b}=\mu$ and the alternative hypothesis is $H_{0}: \mu_{b}>\mu$, where $\mu_{b}$ is the mean annual return for buy transactions and $\mu$ is the unconditional mean annual return. The test statistic is given by

$$
Z_{b}=\frac{\bar{r}_{b}-\mu}{\sqrt[\sigma_{b}]{\frac{1}{n_{b}}}}
$$

where $\overline{r_{b}}$ is the sample mean annual return for buy transactions, $n_{b}$ is the number of buy signals generated, and $\sigma_{b}$ is the standard deviation of annual return.

Given large sample size, $z_{b}$ is distributed as $N(0,1)$ if the null hypothesis is true. Accordingly, given the critical normal value $z_{\alpha}$, if $Z_{b}>z_{\alpha}$, we reject $H_{0}: \mu_{b}=\mu$ and conclude that the mean annual return for buy transactions is greater than the unconditional mean annual return at $\alpha$ level of significance. For one-tailed test, the significance level is set at 0.05 and 0.01 . Hence, from standard normal table, $z_{0.05}=$ 1.64 and $z_{0.01}=2.33$.

\section{Data and Summary Statistics}

The three data series used are closing prices of the STI, interest rates on Singapore's money market account, and dividend yield proxies for the STI. The first two series were obtained from the database of Taiwan Economic Journal and the third series was obtained through estimation using the algorithm of Fama and French (1988). To gauge the progress of the reform and liberalization measures implemented after the crisis, we partition the 1988-2007 sample period into two sub-periods - nine years (1988-1996) before the crisis and nine years (1999-2007) after the crisis. There are two reasons for not including the 1997-1998 data ${ }^{13}$ in our study. First, it is evident from the title of our paper that this study focuses on the Singapore stock market before and after the Asian financial crisis. Hence, it is

\footnotetext{
${ }^{12} \mathrm{~A}$ two-tailed hypothesis test is not used because it is not relevant to test an alternative hypothesis $H_{\alpha}$ : $\mu_{b}(j)<\mu(j)$ for buy transactions.

${ }^{13}$ However, to investigate the robustness of our results, we will re-examine in Subsection 4.4 the annual returns for the three trading rules by including the 1997-1998 data in our study.
} 
Figure 1. Straits Times Index (1988-2007)

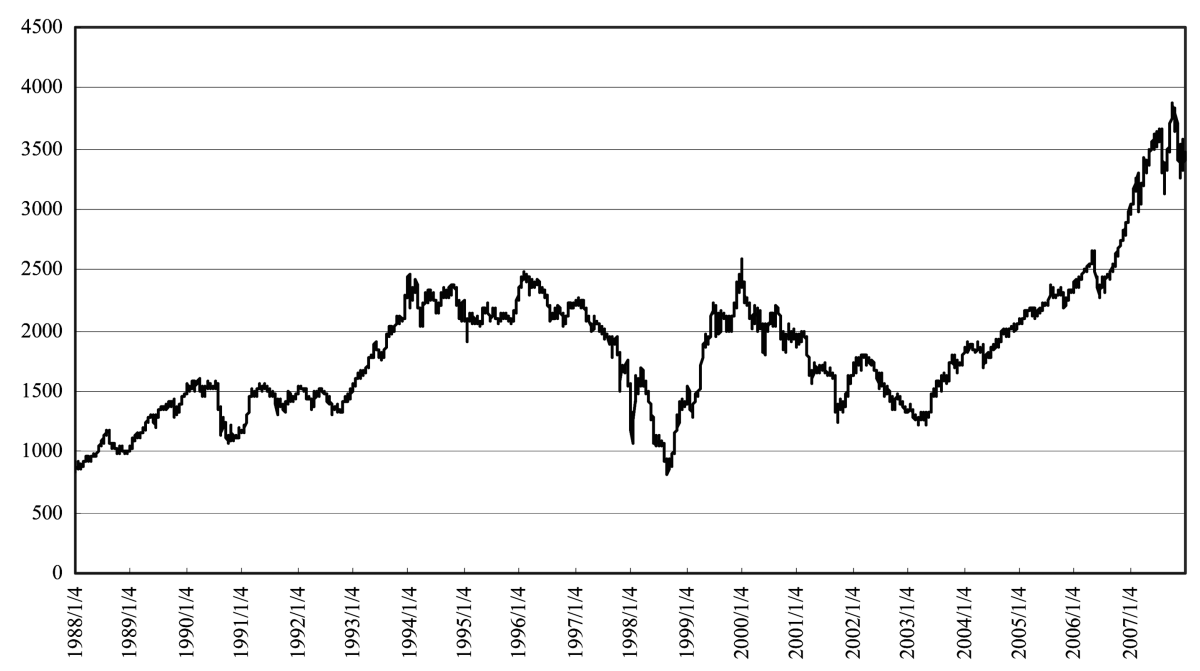

more appropriate not to include the data in this study so as to bring out, if any, contrasting difference in results before and after the crisis. Second, the data are not included in order to eliminate the effect of the crisis on the results.

Figure 1 shows the Straits Times Index from the first trading day in 1988 to the last trading day in 2007. Table 1 contains summary statistics for the entire 19882007 sample period and the two sub-periods for daily returns on the STI. Returns are computed as log differences of the STI level. That is,

$$
R_{t+j}=\log \left(P_{t+j}\right)-\log \left(P_{t}\right)
$$

where $P_{t}$ and $P_{t+j}$ are the closing prices of the STI on day $t$ and day $t+j$, and is the return for the period from day $t$ to day $t+j$. Table 1 shows that the estimated daily autocorrelation for the 1988-1996 sub-period is statistically significant at 1\% level for a two-tailed test at lags 1, 2, and 3; whereas that for the 1999-2007 sub-period is statistically significant merely at 5\% level at lags 1 and 3 . This suggests that the Singapore stock market before the crisis was relatively more at odds with the notion of efficient markets than that after the crisis.

\section{Empirical Results}

If the Singapore stock market is efficient, then the three trading rules should not be able to generate abnormal returns. In the following, we will use the annual 
Table 1. Summary Statistics for Daily Returns

\begin{tabular}{lccc}
\hline & $1988-2007$ & $1988-1996$ & $1999-2007$ \\
\hline Number of Observations & 5001 & 2235 & 2266 \\
Number of Trading Days a Year & 250 & 248 & 252 \\
Mean Daily Return & 0.000285 & 0.000438 & 0.000400 \\
Daily Standard Deviation & 0.012459 & 0.010411 & 0.012054 \\
$\rho(1)$ & $0.093213^{* *}$ & $0.102153^{* *}$ & $0.034632^{*}$ \\
$\rho(2)$ & 0.022472 & $0.050215^{* *}$ & -0.012845 \\
$\rho(3)$ & 0.014943 & $-0.034228^{* *}$ & $0.028632^{*}$ \\
$\rho(4)$ & 0.007217 & -0.001325 & 0.022716 \\
$\rho(5)$ & -0.020832 & $-0.024293^{*}$ & -0.003124 \\
\hline Notes: $\rho(i)$ is the estimated autocorrelation at lag i for each series, where $i=1,2,3,4$, and 5. Numbers \\
with * $(* *)$ are significant at 5\% (1\%) level for a two-tailed test.
\end{tabular}

returns for a buy-and-hold (BH) strategy as a benchmark and examine the annual returns for each of the three trading rules. For the 1988-1996 sub-period, the annual return for the BH strategy is 0.1087 if trading costs are excluded and 0.1064 if they are included. For the 1999-2007 sub-period, the annual return for the BH strategy is 0.1007 if trading costs are excluded and 0.0984 if they are included.

\section{A. Results for Simple Moving Average Rules}

Table 2 shows the annual returns and the numbers of buy transactions for the 10 simple MA rules (with $0 \%$ band and $1 \%$ band) for the two sub-periods. The simple MA rules are identified as (price, average, band), where price is the closing price of the STI, average is the length of the moving average, and band is the percentage difference needed to generate a buy signal.

For the 1988-1996 sub-period, with trading costs excluded, the annual returns range from 0.0926 to 0.1378 for the five MA rules with $0 \%$ band and from 0.1019 to 0.1428 for the five MA rules with $1 \%$ band. The average annual return is 0.1234 for these $10 \mathrm{MA}$ rules, which beats the annual return of 0.1087 for the BH strategy. Using a one-tailed test, the annual returns for seven of the 10 simple MA rules are significant at either $5 \%$ or $1 \%$ level. With trading costs included, the annual returns range from 0.0816 to 0.1231 for the five MA rules with $0 \%$ band and from 0.0899 to 0.1262 for the five MA rules with $1 \%$ band. The average annual return is 0.1110 for the $10 \mathrm{MA}$ rules, which is only slightly larger than the annual return of 0.1064 for the BH strategy. Using a one-tailed test, the annual returns for two of the 10 simple MA rules are significant at $5 \%$ level.

However, the 1999-2007 results are noticeably different from the 1988-1996 
Table 2. Annual Returns for Simple Moving Average Rules

\begin{tabular}{|c|c|c|c|c|c|c|}
\hline \multirow[b]{2}{*}{ Trading Costs } & \multicolumn{2}{|c|}{ 1988-1996 } & \multicolumn{4}{|c|}{ 1999-2007 } \\
\hline & excluded & included & N(buy) & excluded & included & $\mathrm{N}$ (buy) \\
\hline BH strategy & 0.1087 & 0.1064 & & 0.1007 & 0.0984 & \\
\hline \multicolumn{7}{|l|}{ Simple MAs } \\
\hline \multirow[t]{2}{*}{$(1,20,0 \%)$} & 0.0926 & 0.0816 & 109 & 0.0751 & 0.0686 & 98 \\
\hline & $(-1.6782)$ & $(-2.0987)$ & & $(-2.0483)$ & $(-2.3807)$ & \\
\hline \multirow[t]{2}{*}{$(1,50,0 \%)$} & 0.1315 & 0.1172 & 50 & 0.0944 & 0.0828 & 58 \\
\hline & $(2.0957)^{*}$ & $(1.0253)$ & $(-0.4281)$ & $(-1.6998)$ & & \\
\hline \multirow[t]{2}{*}{$(1,100,0 \%)$} & 0.1378 & 0.1231 & 32 & 0.0856 & 0.0764 & 39 \\
\hline & $(2.4195)^{* *}$ & $(1.7108)^{*}$ & $(-1.6508)$ & $(-1.8446)$ & & \\
\hline \multirow[t]{2}{*}{$(1,150,0 \%)$} & 0.1182 & 0.1040 & 44 & 0.1143 & 0.1024 & 36 \\
\hline & (1.0456) & $(-0.2104)$ & $(1.6547)^{*}$ & $(0.3265)$ & & \\
\hline \multirow[t]{2}{*}{$(1,200,0 \%)$} & 0.1241 & 0.1177 & 35 & 0.0912 & 0.0800 & 41 \\
\hline & $(1.7049)^{*}$ & (1.1756) & $(-0.9486)$ & $(-1.7569)$ & & \\
\hline \multirow[t]{2}{*}{$(1,20,1 \%)$} & 0.1019 & 0.0899 & 98 & 0.0810 & 0.0725 & 87 \\
\hline & $(-0.7450)$ & $(-1.7742)$ & $(-1.8565)$ & $(-2.0542)$ & & \\
\hline \multirow[t]{2}{*}{$(1,50,1 \%)$} & 0.1331 & 0.1174 & 44 & 0.0978 & 0.0882 & 51 \\
\hline & $(2.1746)^{*}$ & (1.0989) & $(-0.2182)$ & $(-1.1041)$ & & \\
\hline \multirow[t]{2}{*}{$(1,100,1 \%)$} & 0.1428 & 0.1262 & 27 & 0.0835 & 0.0747 & 32 \\
\hline & $(2.7052)^{* *}$ & $(1.9485)^{*}$ & $(-1.7764)$ & $(-1.9294)$ & & \\
\hline \multirow[t]{2}{*}{$(1,150,1 \%)$} & 0.1244 & 0.1196 & 38 & 0.1091 & 0.0957 & 29 \\
\hline & $(1.7538)^{*}$ & $(1.3472)$ & $(0.8846)$ & $(-0.1640)$ & & \\
\hline \multirow[t]{2}{*}{$(1,200,1 \%)$} & 0.1279 & 0.1131 & 31 & 0.1052 & 0.0941 & 34 \\
\hline & $(1.8547)^{*}$ & $(0.6211)$ & $(0.3709)$ & $(-0.3305)$ & & \\
\hline Average & 0.1234 & 0.1110 & & 0.0937 & 0.0835 & \\
\hline
\end{tabular}

Note: The simple moving average rules are identified as (price, average, band), where price is the closing price of the STI, average is the length of the moving average, and band is the percentage difference needed to generate a buy signal. N(buy) is the number of buy transactions generated. Figures in parentheses are standard $\mathrm{z}$ values testing the difference of mean buy return from unconditional mean annual return. Figures with $*(* *)$ are significant at $5 \%(1 \%)$ level for a one-tailed test.

results. For the 1999-2007 sub-period, with trading costs excluded, seven of the 10 MA rules yield an annual return that is less than the annual return of 0.1007 for the BH strategy. The average annual return is only 0.0937 for these 10 MA rules, which is almost 0.7 percent smaller than that for the BH strategy. Using a onetailed test, the annual return for only one of the 10 simple MA rules is significant at $5 \%$ level. With trading costs included, nine of the 10 MA rules yield an annual return that is less than the annual return of 0.0984 for the BH strategy. Again, the average annual return of 0.0835 for the $10 \mathrm{MA}$ rules is about 1.5 percent smaller than that for the BH strategy. Using a one-tailed test, the annual return for none of 
the 10 simple MA rules is significant at either $5 \%$ or $1 \%$ level. Obviously, in terms of annual return, the 10 simple MA rules perform better for 1988-1996 than for 1999-2007.

\section{B. Results for Dual Moving Average Rules}

Table 3 shows the annual returns and the numbers of buy transactions for the 10 dual MA rules for the two sub-periods. The dual MA rules are identified as (short, long, band), where short and long are the lengths of the short and long moving averages respectively, and band is the percentage difference needed to generate a buy signal.

Table 3. Annual Returns for Dual Moving Average Rules

\begin{tabular}{ccccccc}
\hline & \multicolumn{2}{c}{$1988-1996$} & & \multicolumn{2}{c}{$1999-2007$} \\
Trading Costs & excluded & included & N(buy) & excluded & included & N(buy) \\
\hline BH strategy & 0.1087 & 0.1064 & & 0.1007 & 0.0984 & \\
Dual MAs & & & & & & \\
$(2,20,0 \%)$ & 0.1043 & 0.0923 & 101 & 0.0865 & 0.0773 & 93 \\
& $(-0.3291)$ & $(-1.5890)$ & & $(-1.6051)$ & $(-1.9087)$ & \\
$(2,50,0 \%)$ & 0.0875 & 0.0763 & 48 & 0.0813 & 0.0723 & 52 \\
& $(-1.9840)$ & $(-2.4181)$ & & $(-1.9463)$ & $(-2.1402)$ & \\
$(5,100,0 \%)$ & 0.1265 & 0.1132 & 36 & 0.1142 & 0.1013 & 38 \\
& $(1.7603)^{*}$ & $(0.6546)$ & & $(1.6495)$ & $(0.2140)$ & \\
$(5,150,0 \%)$ & 0.1377 & 0.1232 & 29 & 0.1098 & 0.0972 & 33 \\
& $(2.3504)^{* *}$ & $(1.7284)$ & & $(0.8568)$ & $(-0.0657)$ & \\
$(5,200,0 \%)$ & 0.1202 & 0.1057 & 24 & 0.0944 & 0.0847 & 27 \\
& $(1.2468)$ & $(-0.1467)$ & & $(-0.6162)$ & $(-1.4169)$ & \\
$(2,20,1 \%)$ & 0.0985 & 0.0874 & 92 & 0.0874 & 0.0775 & 84 \\
& $(-1.1426)$ & $(-1.9743)$ & & $(-1.2462)$ & $(-1.8864)$ & \\
$(2,50,1 \%)$ & 0.0916 & 0.0808 & 41 & 0.0835 & 0.0741 & 46 \\
& $(-1.7535)$ & $(-2.1092)$ & & $(-1.8216)$ & $(-1.9843)$ & \\
$(5,100,1 \%)$ & 0.1317 & 0.1161 & 29 & 0.1094 & 0.0980 & 31 \\
& $(1.9489) *$ & $(0.9638)$ & & $(0.7864)$ & $(-0.0138)$ & \\
$(5,150,1 \%)$ & 0.1324 & 0.1177 & 22 & 0.1241 & 0.1099 & 25 \\
& $(2.0944)^{*}$ & $(1.1479)$ & & $(2.1669)$ & $(1.0415)$ & \\
Average & 0.1157 & 0.1027 & 19 & 0.0900 & 0.0798 & 21 \\
& $(0.6672)$ & $(-0.3667)$ & & $(-1.0047)$ & $(-1.8046)$ & \\
& 0.1146 & 0.1015 & & 0.0981 & 0.0872 & \\
\hline
\end{tabular}

Notes: The dual moving average rules are identified as (short, long, band), where short and long are the lengths of short and long moving averages, respectively, and band is the percentage difference needed to generate a buy signal. $\mathrm{N}$ (buy) is the number of buy transactions generated. Figures in parentheses are standard $\mathrm{z}$ values testing the difference of mean buy return from unconditional mean annual return. Figures with $*(* *)$ are significant at $5 \%(1 \%)$ level for a one-tailed test. 
The results in Table 3 exhibit similar patterns to those in Table 2. For 19881996, the average annual return for the 10 MA rules is 0.1146 if trading costs are excluded and 0.1015 if they are included. Using a one-tailed test, the annual returns for four of the $10 \mathrm{MA}$ rules are significant at either 5\% or $1 \%$ level if trading costs are excluded and the annual return for only one MA rule is significant at 5\% level if they are included. For 1999-2007, the average annual return for the 10 MA rules is 0.0981 if trading costs are excluded and only 0.0872 if they are included. Again, using a one-tailed test, the annual return for only one MA rule is significant at 5\% level if trading costs are excluded and the annual return for none of the $10 \mathrm{MA}$ rules is significant at either $5 \%$ or $1 \%$ level if they are included. That is, on average, the 10 dual MA rules perform no better than the BH strategy for 19992007 -- whether or not trading costs are included in the calculations.

\section{Results for Trading Range Breakout Rules}

Table 4 reports the annual returns and the numbers of buy transactions for the 10 TRB rules for the two sub-periods. The TRB rules are identified as (day, band), where day is the number of prior days used to record a maximum or a minimum price, and band is the percentage difference needed to generate a buy signal.

Again, the $10 \mathrm{TRB}$ rules generate annual returns similar to those for simple and dual MA rules. That is, like the two MA rules, the TRB rules are more effective for 1988-1996 than for 1999-2007. For the 1988-1996 sub-period, the average annual return for the 10 TRB rules is 0.1284 if trading costs are excluded and 0.1149 if they are included. Using a one-tailed test, the annual returns for seven of the 10 TRB rules are significant at either 5\% or $1 \%$ level if trading costs are excluded and the annual returns for two TRB rules are significant at 5\% level if they are included. Hence, for 1988-1996, the 10 TRB rules perform markedly better than the BH strategy, especially if trading costs are excluded. For the 1999-2007 subperiod, the average annual return is 0.1042 if trading costs are excluded and 0.0928 if they are included. Again, using a one-tailed test, the annual return for only one TRB rule is significant at 5\% level if trading costs are excluded and the annual return for none of the $10 \mathrm{TRB}$ rules is significant at either $5 \%$ or $1 \%$ level if they are included. Hence, for 1999-2007, the 10 TRB rules perform no better than the $\mathrm{BH}$ strategy, especially if trading costs are included in the calculations.

\section{Robustness of the Results}

The above results are obtained by excluding the 1997-1998 data in our study. To 
Table 4. Annual Returns for Trading Range Breakout Rules

\begin{tabular}{|c|c|c|c|c|c|c|}
\hline \multirow[b]{2}{*}{ Trading Costs } & \multicolumn{2}{|c|}{ 1988-1996 } & \multicolumn{4}{|c|}{ 1999-2007 } \\
\hline & excluded & included & N(buy) & excluded & included & $\mathrm{N}$ (buy) \\
\hline BH strategy & 0.1087 & 0.1064 & & 0.1007 & 0.0984 & \\
\hline \multicolumn{7}{|l|}{ TRB rules } \\
\hline \multirow[t]{2}{*}{$(20,0 \%)$} & 0.1024 & 0.0963 & 64 & 0.0885 & 0.0792 & 61 \\
\hline & $(-0.5146)$ & $(-0.9742)$ & & $(-1.1206)$ & $(-1.8064)$ & \\
\hline \multirow[t]{2}{*}{$(50,0 \%)$} & 0.1285 & 0.1149 & 42 & 0.1088 & 0.0964 & 39 \\
\hline & $(1.7752)^{*}$ & $(0.8145)$ & & (0.8490) & $(-0.1426)$ & \\
\hline \multirow[t]{2}{*}{$(100,0 \%)$} & 0.1328 & 0.1178 & 35 & 0.1143 & 0.1024 & 32 \\
\hline & $(2.1594)^{*}$ & (1.0961) & & (1.4877) & $(0.3743)$ & \\
\hline \multirow{2}{*}{$(150,0 \%)$} & 0.1194 & 0.1072 & 38 & 0.1032 & 0.0924 & 41 \\
\hline & (1.1480) & $(0.0546)$ & & $(0.2168)$ & $(-0.7441)$ & \\
\hline \multirow[t]{2}{*}{$(200,0 \%)$} & 0.1316 & 0.1180 & 30 & 0.0954 & 0.0846 & 34 \\
\hline & $(1.9231)^{*}$ & (1.2208) & & $(-0.4525)$ & $(-1.4879)$ & \\
\hline \multirow[t]{2}{*}{$(20,1 \%)$} & 0.1165 & 0.1034 & 58 & 0.0922 & 0.0826 & 57 \\
\hline & $(0.8043)$ & $(-0.2877)$ & & $(-0.7811)$ & $(-1.6305)$ & \\
\hline \multirow[t]{2}{*}{$(50,1 \%)$} & 0.1414 & 0.1254 & 39 & 0.1063 & 0.0939 & 34 \\
\hline & $(2.4589)^{\text {** }}$ & $(1.7043)^{*}$ & & $(0.5438)$ & $(-0.5092)$ & \\
\hline \multirow[t]{2}{*}{$(100,1 \%)$} & 0.1493 & 0.1324 & 32 & 0.1204 & 0.1073 & 29 \\
\hline & $(2.7688)^{* *}$ & $(2.1870)^{*}$ & & $(1.9372)^{*}$ & $(0.7860)$ & \\
\hline \multirow[t]{2}{*}{$(150,1 \%)$} & 0.1254 & 0.1123 & 34 & 0.1083 & 0.0960 & 36 \\
\hline & $(1.6987)^{*}$ & $(0.5434)$ & & $(0.7894)$ & $(-0.1877)$ & \\
\hline \multirow[t]{2}{*}{$(200,1 \%)$} & 0.1362 & 0.1209 & 27 & 0.1045 & 0.0936 & 31 \\
\hline & $(2.2865)^{*}$ & (1.4149) & & $(0.2893)$ & $(-0.5438)$ & \\
\hline Average & 0.1284 & 0.1149 & & 0.1042 & 0.0928 & \\
\hline
\end{tabular}

Notes: The trading range breakout rules are identified as (day, band), where day is the number of past days used to record a maximum or a minimum price, and band is the percentage difference needed to generate a buy signal. $\mathrm{N}$ (buy) is the number of buy transactions generated. Figures in parentheses are standard $\mathrm{z}$ values testing the difference of mean buy return from unconditional mean annual return. Figures with $*(* *)$ are significant at $5 \%(1 \%)$ level for a one-tailed test.

investigate the robustness of our results, we re-examine the annual returns for the three trading rules by including the data. To avoid distracting our attention from the main focus (i.e., with the two-year data excluded) of this study, our robustness discussion will be brief. Detailed results with the 1997-1998 data included are available upon request.

Evidently, the Asian financial crisis exerted strong downward pressure on the STII for the 1997-1998 period. For 1988-1997, the annual return for the BH strategy is 0.0607 if trading costs are excluded and 0.0587 if they are included almost 4.8 percentage points smaller than if the 1997 data are excluded. For 1998- 
2007, the annual return for the BH strategy is 0.0825 if trading costs are excluded and 0.0805 if they are included - around 1.8 percentage points smaller than if the 1998 data are excluded.

For the 10 simple MA rules, the average annual return for $1988-1997$ is 0.0887 if trading costs are excluded and 0.0782 if they are included, and that for 19982007 is 0.0866 if trading costs are excluded and 0.0772 if they are included. For the 10 dual MA rules, the average annual return for 1988-1997 is 0.0843 if trading costs are excluded and 0.0741 if they are included, and that for 1998-2007 is 0.0874 if trading costs are excluded and 0.0782 if they are included. For the 10 TRB rules, the average annual return for 1988-1997 is 0.0947 if trading costs are excluded and 0.0858 if they are included, and that for $1998-2007$ is 0.0882 if trading costs are excluded and 0.0801 if they are included.

Apparently, for the three trading rules, there are no significant differences in average annual return between the two sub-periods. However, using the annual returns for the $\mathrm{BH}$ strategy as a benchmark, the three rules generally perform better than the BH strategy for 1988-1997, but they perform, on average, no better than the BH strategy for 1998-2007 -- especially if trading costs are taken into account. For example, consider the one-tailed hypothesis tests when trading costs are included. For 1988-1997, the annual returns for seven simple MA rules, six dual MA rules, and eight TRB rules are significant at either 5\% or $1 \%$ level. However, for 1998-2007, the annual returns for one simple MA rule, one dual MA rule and two TRB rules are significant at only 5\% level. Hence, with the 1997-1998 data included, our conclusion that the efficiency of the Singapore stock market has been enhanced after the crisis still holds.

\section{Conclusions}

In the aftermath of the Asian financial crisis, the Monetary Authority of Singapore (MAS) and the Singapore government have implemented a series of reform and liberalization measures intended to upgrade its financial markets. In this study, we investigate whether those measures have led to less profitability for those investors who use technical rules for trading stocks. To proceed, we divide the 1988-2007 sample period into two equal sub-periods - nine years (1988-1996) before the crisis and nine years (1999-2007) after the crisis - and examine whether there is obvious difference in annual return for three trading rules between the two sub-periods. 
Our empirical results ${ }^{14}$ show that, on average, the three trading rules - simple moving average, dual moving average, and trading range breakout - consistently generate higher annual returns for the 1988-1996 sub-period than those for the 1999-2007 sub-period. In addition, using the annual returns for a buy-and-hold (BH) strategy as a benchmark, the three trading rules generally perform better than the BH strategy for 1988-1996 but perform no better than the BH strategy for 1999-2007.

Sharpe et al. (1999) assert that, in an efficient market, "publicly known investment strategies cannot be expected to generate abnormal returns." Given our empirical findings, the MAS and the Singapore government can take some credit for the fact that their reform and liberalization measures implemented after the 1997-1998 crisis have, to a certain degree, ${ }^{15}$ improved the efficiency of the stock market. The end result is that investors nowadays cannot expect to make abnormal returns in the Singapore stock market.

\section{Acknowledgements}

We are grateful to Andrew Carverhill of the University of Hong Kong, K. C. Chan, Kalok Chan, Susheng Wang, and John Wei of the Hong Kong University of Science and Technology for helpful comments and suggestions.

Received 14 April 2008, Revised 6 June 2008, Accepted 18 June 2008

\footnotetext{
${ }^{14}$ As mentioned in footnote 10, our objective differs from that of Brock et al. (1992). In a way, our 19881996 results are similar to those of Brock et al. in that both studies indicate that, in general, buy signals generate higher returns than those for the buy-and-hold strategy. This similarity, however, does not hold for our 1999-2007 results.

${ }^{15}$ Although we cannot claim, based on our present findings, that those reform and liberalization measures implemented after the Asian financial crisis are solely responsible for improving the efficiency of the Singapore stock market, they are certainly the most important force that has led to its efficiency.
} 


\section{References}

Bailey, W., Stulz, R., Yen, S.(1990), "Properties of Daily Stock Returns from the Pacific Basin Stock Markets: Evidence and Implications", in S. Rhee and R. Chang (ed.), Pacific-Basin Capital Markets Research, Vol. I, North-Holland, pp. 155-171.

Bessembinder, H., Chan, K.(1995), “The Predictability of Technical Trading Rules in the Asian Stock Markets”, Pacific-Basin Finance Journal, Vol. 3, pp. 257-284.

Bessembinder, H., Chan, K.(1998), "Market Efficiency and the Returns to Technical Analysis", Financial Management, Vol. 27, pp. 5-17.

Brock, W., Lakonishok, J., LeBaron, B.(1992), "Simple Technical Trading Rules and the Stochastic Properties of Stock Returns", Journal of Finance, Vol. 47, pp. 1731-1764.

Fama, E. F.(1970), "Efficient Capital Markets: A Review of Theory and Empirical Work", Journal of Finance, Vol. 25, pp. 383-417.

Fama, E. F.(1991), "Efficient Capital Markets: II", Journal of Finance, Vol. 46, pp. 1575-1617.

Fama, E. F., French, K.(1988), "Dividend Yields and Expected Stock Returns", Journal of Financial Economics, October, pp. 3-26.

Fernandez-Rodriguez, F., Gonzalez-Martel, C., Sosvilla-Rivero, S.(2000), "On the Profitability of Technical Trading Rules based on Artificial Neural Networks: Evidence from the Madrid Stock Market”, Economics Letters, Vol. 69, pp. 89-94.

Huang, B. N.(1995), "Do Asian Stock Market Prices follow Random Walks? Evidence from Variance Ratio Test", Applied Financial Economics, Vol. 5, pp. 251-256.

Hudson, R., Dempsey, M., Keasey, K.(1996), “A Note on the Weak Form Efficiency of Capital Markets: the Application of Simple Technical Trading Rules to UK Stock Prices - 1935 to 1994", Journal of Banking and Finance, Vol. 20, pp. 1121-1132.

Kester, G. W.(1990), A Comparative Analysis of the Potential Gains from Market Timing in the United States and Singapore, in M Ariff and L W Johnson, (ed.), Securities Markets and Stock Pricing: Evidence from a Developing Market in Asia, Longman Singapore Publishers Ltd., Singapore.

Kim, E. H., Singal, V.(1997), "Are Open Markets Good for Foreign Investors and Emerging Nations?" Journal of Applied Corporate Finance, Vol. 10, pp. 18-33.

Kim, E. H. (2003), "Globalization of Capital Markets and the Asian Financial Crisis", in J. M. Stern and D. H. Chew (ed.), The Revolution in Corporate Finance, 4th edition, Blackwell Publishing, pp. 461-471.

LeRoy, S. F(1982), "Expectations Models of Asset Prices: a Survey of Theory", Journal of Finance, Vol. 37, pp. 185-217.

Pan, M., Chiou, J., Hocking, R., Rim, H.(1991), An Examination of Mean-Reverting Behavior of Stock Prices in Pacific-Basin Stock Markets, in S. Rhee and R. Chang (ed.), Pacific-Basin Capital Markets Research, Vol. II. North-Holland, Amersterdam, pp. 333-343.

Sharpe, W. F., Alexander, G. J., Bailey, J. V.(1999), Investments, 6th edition, Prentice Hall, Inc. Siegel, J. J. (2002), Stocks for the Long Run, 3rd edition, McGraw-Hill. 